\title{
Intra and post-operative complications observed with femtosecond laser-assisted cataract surgery versus conventional phacoemulsification surgery: a systematic review and meta-analysis
}

Jinhua Wang ${ }^{1 *+}$, Fanfan Su ${ }^{1 \dagger}$, Yong Wang ${ }^{2}$, Yao Chen ${ }^{1}$, Qiao Chen ${ }^{1}$ and Fen $\mathrm{Li}^{1}$

\begin{abstract}
Background: In this analysis, we aimed to systematically compare the complications which were associated with femtosecond laser-assisted cataract surgery (FLACS) versus the conventional phacoemulsification surgery (CPE).

Methods: Commonly used search databases, specifically MEDLINE, Cochrane Central, EMBASE, and http://www. clinicaltrials.gov were carefully searched for English publications comparing FLACS versus CPE. The selected endpoints which were assessed included incomplete capsulotomy, anterior capsulotomy tag, anterior capsule tear, posterior capsule tear, injury to the descemet's membrane, zonular dialysis, vitreous loss, macular or corneal edema, and elevated intra-ocular pressure. Statistical analysis was carried out by the latest version of the RevMan software (version 5.3) and represented by risk ratios (RR) with 95\% confidence intervals (CI).
\end{abstract}

Results: A total number of 7156 participants were included. Three thousand five hundred and fifty four (3554) participants were assigned to the FLACS group. The risks for incomplete capsulotomy, anterior capsulotomy tag, and anterior capsular tear were significantly higher with FLACS (RR: $22.42,95 \% \mathrm{Cl}: 4.53-110.82$; $P=0.0001$ ), (RR: 33.07, 95\% Cl: $6.53-167.56 ; \mathrm{P}=0.0001)$ and (RR: $4.74,95 \% \mathrm{Cl}: 2.59-8.68 ; P=0.00001)$ respectively. The risks for macular/corneal edema (RR: 2.05, 95\% Cl: 1.18-3.55; $P=0.01$ ) and elevated intra-ocular pressure (RR: $3.24,95 \% \mathrm{Cl}$ : 1.55-6.78; $P=0.002$ ) were also significantly higher with FLACS. However, the risks for impaired descemet's membrane (RR: $0.95,95 \% \mathrm{Cl}: 0.61-1.47 ; P=0.80$ ), zonular dialysis (RR: $0.40,95 \% \mathrm{Cl}: 0.06-2.72 ; P=0.35$ ), vitreous loss (RR: $0.09,95 \% \mathrm{Cl}: 0.01-1.63 ; P=0.10$ ) and posterior capsular tear (RR: $1.45,95 \% \mathrm{Cl}: 0.23-9.16$; $P=0.69$ ) were not significantly different.

Conclusions: The current results showed that FLACS did not improve intra/post-operative complications in comparison to CPE. Further larger studies should confirm this hypothesis.

Keywords: Femtosecond laser-assisted cataract surgery, Conventional phacoemulsification surgery, Post-operative complications

\footnotetext{
* Correspondence: oculist498474@163.com

${ }^{\dagger}$ Jinhua Wang and Dr Fanfan Su contributed equally to this paper and they are the first co-authors.

${ }^{1}$ Department of Ophthalmology, Jingzhou Central Hospital, Jingzhou, Hubei,

China

Full list of author information is available at the end of the article
}

(c) The Author(s). 2019 Open Access This article is distributed under the terms of the Creative Commons Attribution 4.0 International License (http://creativecommons.org/licenses/by/4.0/) which permits unrestricted use, distribution, and reproduction in any medium, provided you give appropriate credit to the original author(s) and the source, provide a link to the Creative Commons license, and indicate if changes were made. The Creative Commons Public Domain Dedication waiver (http://creativecommons.org/publicdomain/zero/1.0/) applies to the data made available in this article, unless otherwise stated. 


\section{Background}

In this modern developing society, the total number of people undergoing eye surgery is gradually increasing [1]. Agarwal's et al. recent study based on current and effective features of femtosecond laser-assisted cataract surgery (FLACS) showed that surgeons might now be more confident and patients might be more satisfied with FLACS, but however, a few studies showed that this surgery was not a better option when compared to the manual phacoemulsification in terms of outcomes and complications [2]. Several studies aimed to demonstrate which procedure might come out on top but different opinions were noted [3].

In the large, multi-centered European Registry of Quality Outcomes for Cataract and Refractive Surgery (EUREQUO) study, intraoperative complications for FLACS $(0.7 \%)$ were similar in comparison to the manual phacoemulsification surgery (0.4\%) [4].This same study showed postoperative complications to also have been lower with conventional phacoemulsification (3.4\% for FLACS versus $2.3 \%$ for phacoemulsification). However, better outcomes were still expected with this new FLACS.

Currently, we aimed to systematically compare the intra/post-operative complications which were associated with FLACS versus the conventional phacoemulsification surgery (CPE).

\section{Methods}

\section{Search databases}

Commonly used search databases, specifically MEDLINE, Cochrane Central, EMBASE, and http://www.clinicaltrials. gov were carefully searched for English publications comparing FLACS versus CPE. Reference lists of several relevant publications were also carefully reviewed.

\section{Search strategies}

The search terms which were used were limited to the following:

- Femtosecond laser-assisted cataract surgery and conventional phacoemulsification surgery;

- Femtosecond laser-assisted cataract surgery and phacoemulsification surgery;

- Femtosecond laser-assisted cataract surgery and complications;

- Femtosecond laser-assisted cataract surgery and post-operative complications;

- Conventional phacoemulsification surgery and complications;

- Conventional phacoemulsification surgery and post-operative complications;

- Conventional phacoemulsification surgery and intra-operative complications;

- Cataract surgeries and post-operative complications;

- Femtosecond laser-assisted cataract and phacoemulsification post-operative complications.

No abbreviation or other short term was used during this search process.

\section{Inclusion and exclusion criteria}

Studies were considered relevant if they compared the complications (intra/peri/post-operative) associated with FLACS versus CPE.

Studies were excluded if:

Table 1 Outcomes which were reported

\begin{tabular}{|c|c|c|}
\hline Studies (quality assessment by NOS) & Outcomes reported & Type of complication \\
\hline Abell2015 $(* * * * *)[5]$ & $\begin{array}{l}\text { Incomplete capsulotomy, anterior capsulotomy tag, anterior capsule tear, } \\
\text { posterior capsule tear, corneal haze, unstable pupil, iris hooks/malyugin ring }\end{array}$ & Intra-operative \\
\hline Conrad-Hengerer2013 $(* * * * *)[6]$ & Anterior capsule tear, macular edema, elevated intra-ocular pressure & Intra-operative, post-operative \\
\hline Ewe2015 (******) [7] & $\begin{array}{l}\text { Incomplete capsulotomy, anterior capsulotomy tag, anterior capsule tear, } \\
\text { posterior capsule tear, corneal haze, corneal epithelial defects, descemet's } \\
\text { membrane trauma, zonular dialysis, mean uncorrected visual acuity, macular } \\
\text { edema, ocular hypertension, corneal edema }\end{array}$ & Peri-operative \\
\hline Li2018 $(* * * * *)[8]$ & $\begin{array}{l}\text { Miosis, descemet's membrane local detachment, posterior capsular } \\
\text { opacification, corneal edema, anterior chamber flare }\end{array}$ & Intra-operative and post-operative \\
\hline Mastropasqua2014 $\left(^{* * * * * *}\right)[9]$ & $\begin{array}{l}\text { Descemet's membrane detachment, endothelial gaping, epithelial } \\
\text { gaping, endothelial misalignment, epithelial misalignment }\end{array}$ & Post-operative \\
\hline Oakley2016 $\left(^{* * * * *}\right)[10]$ & Uncorrected visual acuity & Post-operative \\
\hline Roberts2018 $(* * * * *)[11]$ & $\begin{array}{l}\text { Anterior capsule tear, descemet membrane tear, iris trauma, residual soft lens } \\
\text { matter, } \\
\text { posterior capsule tear, vitreous loss, zonular dialysis, corneal edema }\end{array}$ & Intra-operative \\
\hline Titiyal2016 (*****) [12] & Vitreous loss, posterior capsular rent, incomplete capsulotomy & Post-operative \\
\hline
\end{tabular}

Abbreviations: NOS Newcastle Ottawa Scale

For quality assessment by the Newcastle Ottawa Scale (NOS), a score is given in terms of stars ranging from a minimum of 1 star (*) to a maximum of 9 stars $(* * * * * * * *)$ based on the quality of the study 


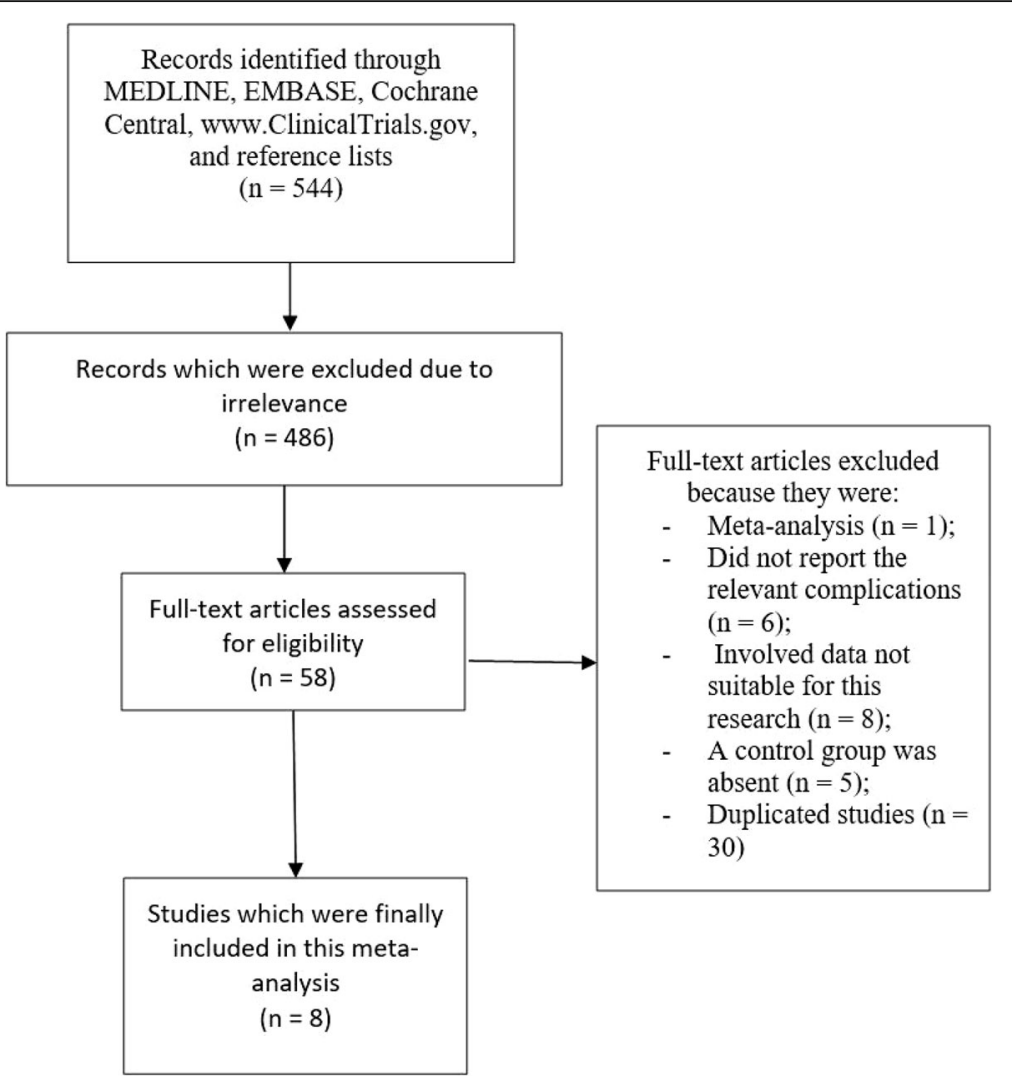

Fig. 1 Flow diagram showing the study selection

- They were meta-analyses, systematic reviews, literature reviews and letters of correspondence;

- They did not report peri/intra or post-operative complications associated with FLACS versus CPE;

- They did not report relevant data which could be used in this analysis;

- They were duplicated studies that repeated in several search databases.

\section{Endpoints which were assessed}

The endpoints which were reported in each study have been listed in Table 1.

The selected endpoints which were assessed included:

- Incomplete capsulotomy;

- Anterior capsulotomy tag;

- Anterior capsule tear;

Table 2 General properties of the studies

\begin{tabular}{|c|c|c|c|c|}
\hline Studies & $\begin{array}{l}\text { Total no of participants } \\
\text { undergoing FLACS (n) }\end{array}$ & $\begin{array}{l}\text { Total no of participants } \\
\text { undergoing CPE (n) }\end{array}$ & $\begin{array}{l}\text { Time period of patients' } \\
\text { enrollment (years) }\end{array}$ & Type of study \\
\hline Abell2015 [5] & 1852 & 2228 & $2012-2013$ & NR prospective \\
\hline Conrad-Hengerer2013 [6] & 73 & 73 & - & Randomized prospective \\
\hline Ewe2015 [7] & 988 & 888 & 2012-2014 & NR prospective \\
\hline Li2018 [8] & 48 & 48 & 2016-2017 & Randomized prospective \\
\hline Mastropasqua2014 [9] & 30 & 30 & - & Randomized prospective \\
\hline Oakley2016 [10] & 323 & 95 & 2012-2014 & NR prospective \\
\hline Roberts2018 [11] & 200 & 200 & - & Randomized prospective \\
\hline Titiyal2016 [12] & 40 & 40 & - & NR prospective \\
\hline Total no (n) & 3554 & 3602 & - & \\
\hline
\end{tabular}

Abbreviations: FLACS femtosecond laser-assisted cataract surgery, CPE conventional phacoemulsification surgery, NR non-randomized 


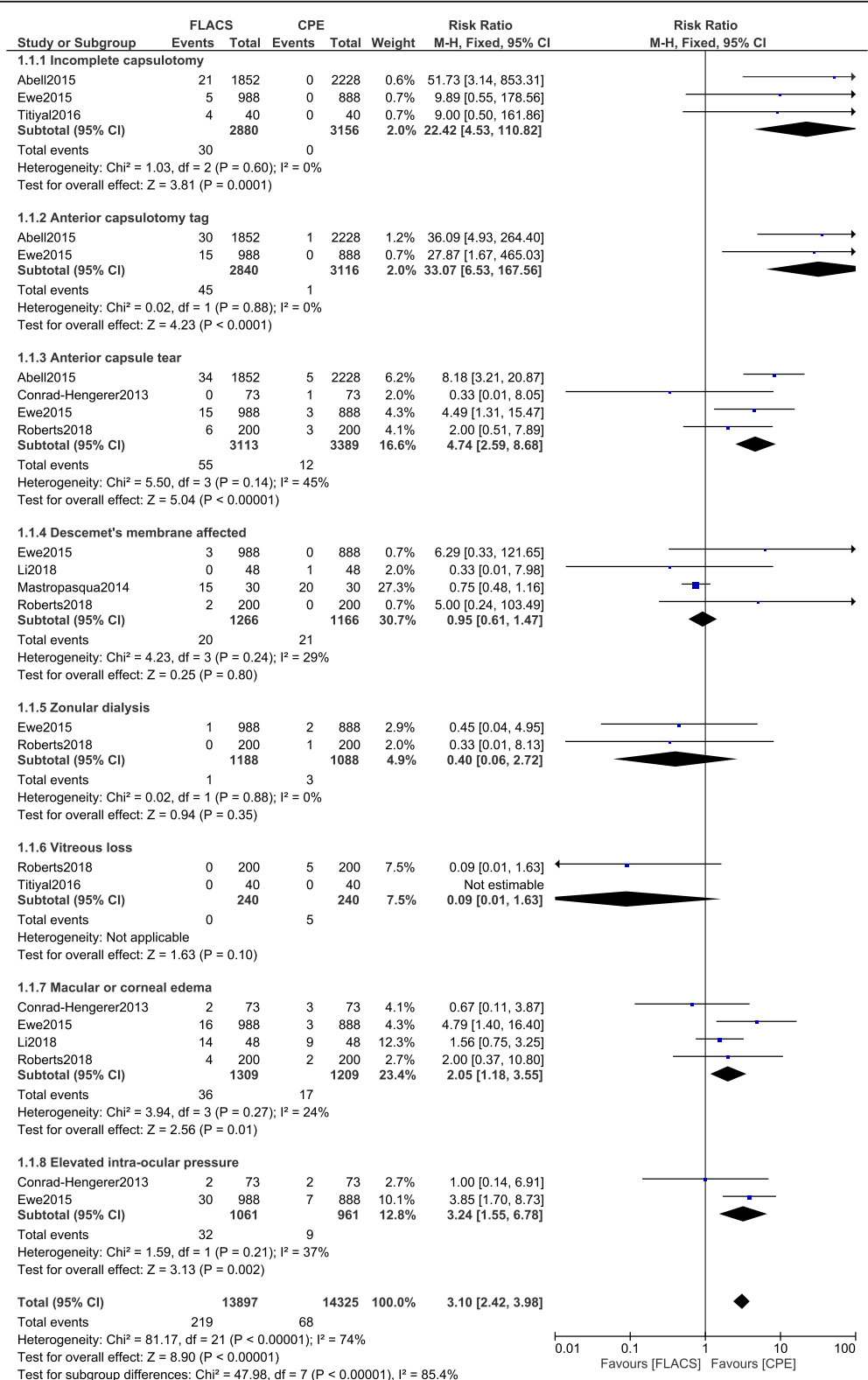

Fig. 2 Intra/post-operative complications associated with femtosecond laser assisted cataract surgery versus conventional phacoemulsification surgery (part I)

- Posterior capsule tear;

- Descemet's membrane impairment;

- Zonular dialysis;

- Vitreous loss;

- Macular or corneal edema;

- Elevated intra-ocular pressure .

\section{Data extraction and quality assessment}

Relevant data were carefully extracted by six independent reviewers. Data included the complications which were assessed with the corresponding number of events, the type of study (randomized or non-randomized prospective), the total number of participants which were assigned to the FLACS and CPE, and the methodological quality of the studies.

The methodological quality of each study was assessed using the Newcastle Ottawa Scale (NOS) [13]. A maximum score of 9 stars was allotted. Scores allotted were based on the quality of the study. The scores have been listed in Table 1. 


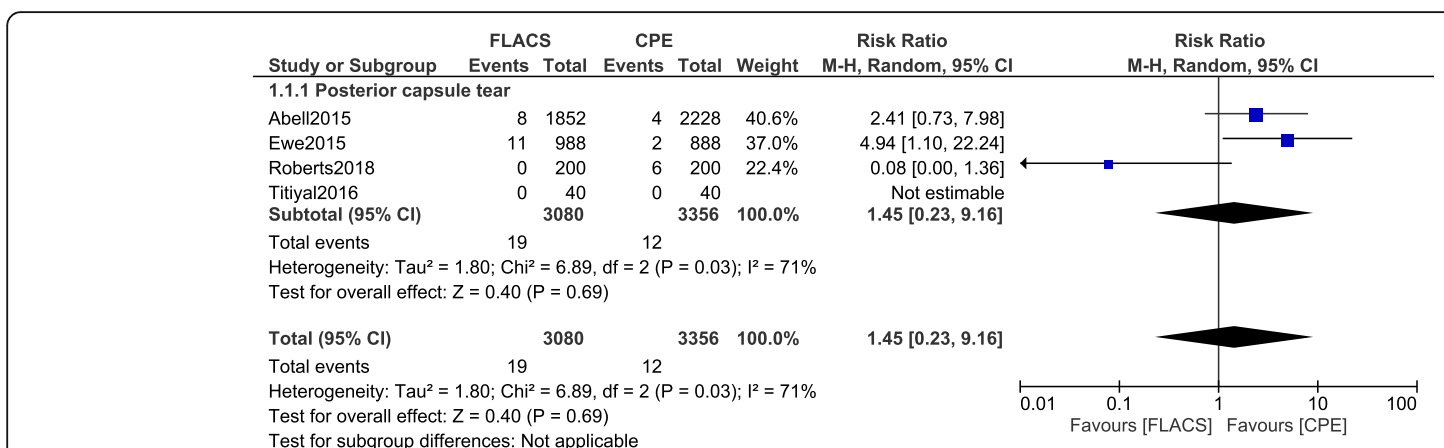

Fig. 3 Intra/post-operative complications associated with femtosecond laser assisted cataract surgery versus conventional phacoemulsification surgery (part II)

\section{Statistical analysis}

The statistical analysis in this research paper was carried out by the latest version of the RevMan software (version 5.3). Risk ratios (RR) with $95 \%$ confidence intervals (CI) were used to represent the data following statistical analysis.

During this analysis, heterogeneity was assessed first of all by the Q statistic test whereby a subgroup analytical result with a $P$ value less or equal to 0.05 was considered as statistically significant and a result with a $P$ value greater than 0.05 was considered statistically insignificant.

In addition, heterogeneity was also assessed by the $\mathrm{I}^{2}$ test. In this case, the lower the $\mathrm{I}^{2}$ value, the lower the heterogeneity, and in contrast, heterogeneity increased with an increasing $\mathrm{I}^{2}$ value.

A fixed statistical effect model was used if the $\mathrm{I}^{2}$ value was less than $50 \%$ or else, a random statistical effect model was used.

Sensitivity analysis was also carried out following the statistical analysis to observe for any significant change and any particular influence of any specific study on the final results.

In addition, publication bias was assessed through visual observation of the funnel plots.

\section{Ethical approval}

This analysis did not involve research with human or animal participants carried out by any of the authors. Hence, an ethical approval was not required for this study.

\section{Results}

\section{Search outcomes}

A total number of 544 studies were obtained from search databases (PRISMA guideline) [14]. A preliminary assessment was carried out where 486 studies were eliminated on a one-time assessment due to irrelevance.

Fifty-eight (58) full-text articles were carefully assessed for eligibility.

Further eliminations were carried out based on the following reasons:

- Meta-analyses (1);

- Studies that did not report intra or post-operative complications (6);

- Studies involving data that were not suitable for this research (8);

- Studies whereby a control group was absent (5);

Table 3 Results of this analysis

\begin{tabular}{llll}
\hline Complications which were analyzed & RR with 95\% Cl & $P$ value & $I^{2}$ value (\%) \\
\hline Incomplete capsulotomy & $22.42[4.53-110.82]$ & 0.0001 & 0 \\
Anterior capsulotomy tag & $33.07[6.53-167.56]$ & 0.0001 & 0 \\
Anterior capsule tear & $4.74[2.59-8.68]$ & 0.00001 & 45 \\
Descemet's membrane affected & $0.95[0.61-1.47]$ & 0.80 & 29 \\
Zonular dialysis & $0.40[0.06-2.72]$ & 0.35 & 0 \\
Vitreous loss & $0.09[0.01-1.63]$ & 0.10 & 0 \\
Macular or corneal edema & $2.05[1.18-3.55]$ & 0.01 & 24 \\
Elevated intra-ocular pressure & $3.24[1.55-6.78]$ & 0.002 & 37 \\
Posterior capsule tear & $1.45[0.23-9.16]$ & 0.69 & 71 \\
\hline
\end{tabular}

Abbreviations: $R R$ risk ratios, $\mathrm{Cl}$ confidence intervals 
- Duplicated studies since they repeated themselves in several different search databases (30).

Finally, 8 prospective studies (randomized and nonrandomized) [5-12] were selected to be included in this analysis as shown in Fig. 1.

\section{General and baseline properties of the studies}

The general properties of the studies have been listed in Table 2.

A total number of 7156 participants were included in this analysis. Three thousand five hundred and fifty four (3554) participants were assigned to the FLACS group whereas 3602 participants were assigned to the CPE group as shown in Table 2. The participants were enrolled from the years 2012 to 2017. The studies were either randomized or non-randomized prospective studies.

\section{Main results}

Following the statistical analysis, the risks for incomplete capsulotomy, anterior capsulotomy tag, and anterior capsular tear were significantly higher with FLACS (RR: 22.42, 95\% CI: 4.53-110.82; $P=0.0001$ ), (RR: 33.07, 95\% CI: 6.53-167.56; $\mathrm{P}=0.0001$ ) and (RR: 4.74, 95\% CI: 2.59-8.68; $P=0.00001$ ) respectively as shown in Fig. 2. The risks for macular/corneal edema (RR: 2.05, 95\% CI: $1.18-3.55 ; P=0.01$ ) and elevated intra-ocular pressure (RR: $3.24,95 \% \mathrm{CI}$ :
1.55-6.78; $P=0.002$ ) were also significantly higher with FLACS.

However, impaired descemet's membrane (RR: 0.95, 95\% CI: $0.61-1.47 ; P=0.80$ ), zonular dialysis (RR: 0.40, 95\% CI: $0.06-2.72 ; P=0.35$ ) and vitreous loss (RR: 0.09, 95\% CI: $0.01-1.63 ; P=0.10)$ were not significantly different as shown in Fig. 2.

The risk for posterior capsular tear (RR: 1.45, 95\% CI: $0.23-9.16 ; P=0.69)$ was also similar as demonstrated in Fig. 3.

Sensitivity analysis was also carried out. Consistent results were obtained throughout with the exception of subgroup assessing for 'posterior capsular tear'. When study Roberts2018 was excluded and another analysis was carried out, the risk for posterior capsular tear (RR: $3.34,95 \%$ CI: $1.32-8.47 ; \quad P=0.01$ ) was significantly higher with FLACS. In addition, when study Ewe2015 was excluded, the risk for macular/corneal edema (RR: 1.43, 95\% CI: $0.76-2.67 ; P=0.26$ ) was not significantly different.

The results have been listed in Table 3.

Low evidence of publication bias was observed as demonstrated by the funnel plot in Fig. 4.

\section{Discussion}

In this current analysis, we compared the intra and postoperative complications which were associated with FLACS versus CPE. The results showed no improvement in complications with the former. FLACS was associated

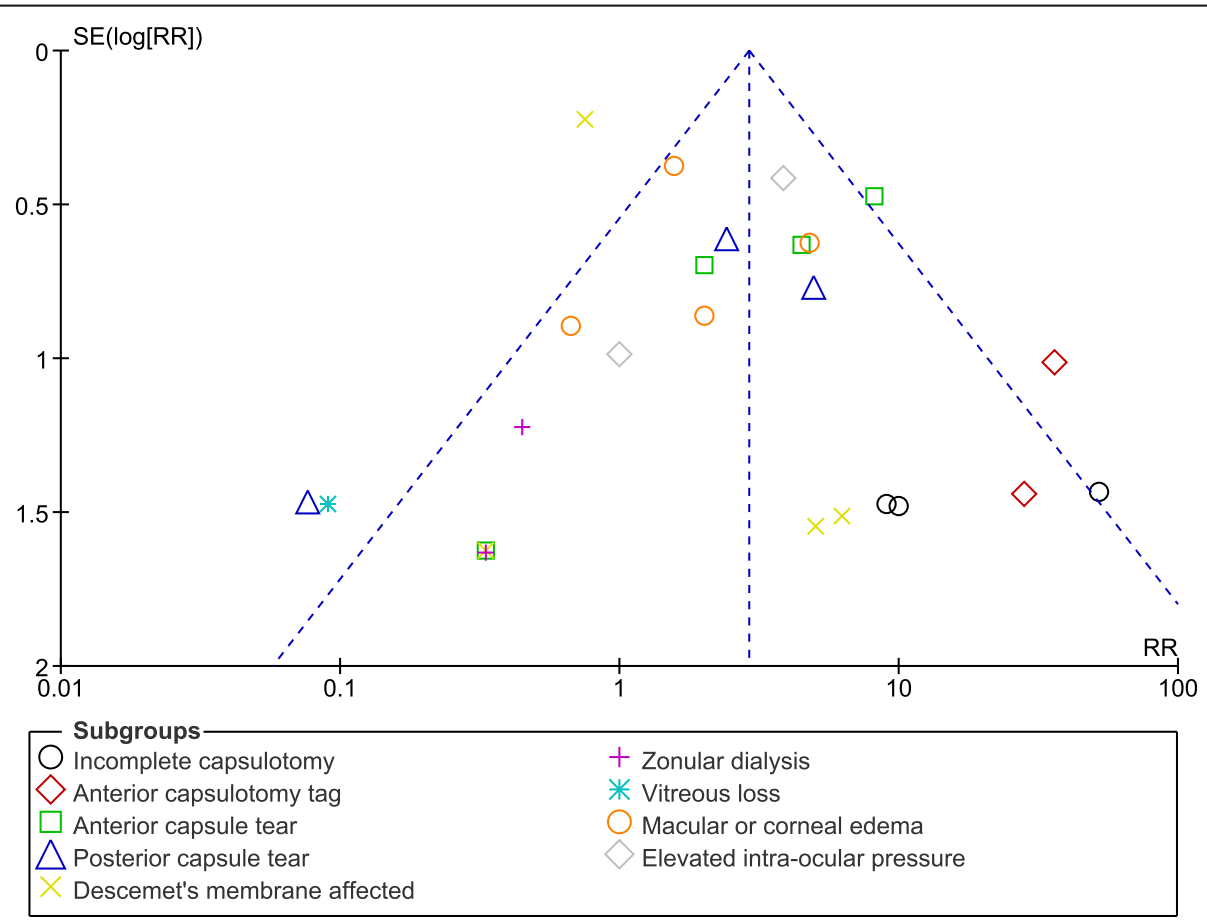

Fig. 4 Funnel plot representing publication bias 
with significantly higher risks of incomplete capsulotomy, anterior capsulotomy tag and anterior capsular tear. The risks for macular/corneal edema, and elevated intra-ocular pressure were also significantly higher with FLACS.

As previously mentioned in the introduction section, in the EUREQUO study [2], intraoperative complications for FLACS $(0.7 \%)$ were similar in comparison to the manual phacoemulsification surgery $(0.4 \%)$. The same study showed postoperative complications to also be lower with CPE (3.4\% for FLACS versus $2.3 \%$ for phacoemulsification) further supporting the results of this analysis.

In addition, another meta-analysis also showed posterior capsular tear to be significantly higher with FLACS in comparison to the manual phacoemulsification surgery again supporting the results of this current analysis [15].

Even if this current analysis did not assess for astigmatism, a retrospective study showed astigmatic changes to be more common with FLACS [16].

However, we should not forget the fact that complications such as vitreous loss might be reduced with FLACS [17] and therefore, its complications should not be overestimated but instead, we should also pay attention to its beneficial features. Also, FLACS using the LenSx laser system might achieve better results in a real world setting [18].

Even though the total number of participants undergoing cataract surgery was sufficient to reach a conclusion, the number of participants were distributed during the subgroup analyses, and hence, only less number of patients participated in each subgroup analysis. However, we could not improve this limitation since only a few original research articles were published on this particular topic. Because of this same reason, data from different randomized and non-randomized prospective studies were pooled together during analysis. There was no other choice or a very biased result with lack of strength would have been obtained. Also, due to a shortage of studies, we included one study comparing cystotome-assisted prechop phacoemulsification surgery versus $C P E$ in this analysis. This might not affected the results to a large extent since the number of participants in the study was very less. Also, there was no specific follow-up time period post-operatively. All the studies which were included in this analysis did not involve the same follow-up time period.

\section{Conclusions}

This current results showed that FLACS did not improve intra/post-operative complications in comparison to CPE. Further larger studies should confirm this hypothesis.

\section{Abbreviations}

Cl: Confidence intervals; CPE: Conventional phacoemulsification surgery;

FLACS: Femtosecond laser-assisted cataract surgery; RR: Risk ratios

\section{Acknowledgements}

Not applicable.

\section{Authors' contributions}

JW, FS, YW, YC, QC and FL were responsible for the conception and design, acquisition of data, analysis and interpretation of data, drafting the initial manuscript and revising it critically for important intellectual content. JW and FS wrote the final manuscript and they are the first co-authors of this manuscript. All the authors have read and approved the final manuscript as it is

\section{Funding}

There was no external funding for this research.

Availability of data and materials

All data and materials used in this research are freely available. References have been provided.

Ethics approval and consent to participate

Ethical approval was not applicable for this systematic review and metaanalysis.

Consent for publication

Not applicable.

\section{Competing interests}

The authors declare that they have no competing interests.

\section{Author details}

'Department of Ophthalmology, Jingzhou Central Hospital, Jingzhou, Hubei, China. ${ }^{2}$ Department of Cataract, Wuhan Aier Eye Hospital, Wuhan, China.

Received: 21 April 2019 Accepted: 31 July 2019

Published online: 09 August 2019

\section{References}

1. Cox JT, Subburaman G, Munoz B, Friedman DS, Ravindran RD. Visual acuity outcomes after cataract surgery: high- vs. low-volume surgeons. Ophthalmology. 2019; Apr 8. pii: 50161-6420(18)31302-2.

2. Agarwal A, Jacob S. Current and effective advantages of femto phacoemulsification. Curr Opin Ophthalmol. 2017;28(1):49-57.

3. Ewe SY, Abell RG, Vote BJ. Femtosecond laser-assisted versus phacoemulsification for cataract extraction and intraocularlens implantation: clinical outcomes review. Curr Opin Ophthalmol. 2018:29(1):54-60.

4. Manning S, Barry P, Henry Y, Rosen P, Stenevi U, Young D, Lundström M. Femtosecond laser-assisted cataract surgery versus standard phacoemulsification cataractsurgery: study from the European registry of quality outcomes for cataract and refractive surgery. J Cataract Refract Surg. 2016:42(12):1779-90

5. Abell RG, Darian-Smith E, Kan JB, Allen PL, Ewe SY, Vote BJ. Femtosecond laser-assisted cataract surgery versus standard phacoemulsification cataractsurgery: outcomes and safety in more than 4000 cases at a single center. J Cataract Refract Surg. 2015;41(1):47-52.

6. Conrad-Hengerer I, Al Juburi M, Schultz T, Hengerer FH, Dick HB. Corneal endothelial cell loss and corneal thickness in conventional compared with femtosecondlaser-assisted cataract surgery: three-month follow-up. J Cataract Refract Surg. 2013;39(9):1307-13.

7. Ewe SY, Abell RG, Oakley CL, Lim CH, Allen PL, McPherson ZE, Rao A, Davies $P E$, Vote BJ. A comparative cohort study of visual outcomes in femtosecond laser-assisted versus phacoemulsification cataract surgery. Ophthalmology. 2016;123(1):178-82.

8. Li X, He Y, Su T, Tian Y, Wang Y, Xia X, Song W. Comparison of clinical outcomes between cystotome-assisted prechop phacoemulsificationsurgery and conventional phacoemulsification surgery for hard nucleus cataracts: a CONSORT-compliant article. Medicine (Baltimore). 2018;97(46):e13124. 
9. Mastropasqua L, Toto L, Mastropasqua A, Vecchiarino L, Mastropasqua R, Pedrotti E, Di Nicola M. Femtosecond laser versus manual clear corneal incision in cataract surgery. J Refract Surg. 2014;30(1):27-33.

10. Oakley CL, Ewe SY, Allen PL, Vote BJ. Visual outcomes with femtosecond laser-assisted cataract surgery versus conventional cataractsurgery in toric IOL insertion. Clin Exp Ophthalmol. 2016;44(7):570-3.

11. Roberts HW, Wagh VK, Sullivan DL, Hidzheva P, Detesan DI, Heemraz BS, Sparrow JM, O'Brart DPS. A randomized controlled trial comparing femtosecond laser-assisted cataract surgery versus conventional phacoemulsification surgery. J Cataract Refract Surg. 2019;45(1):11-20.

12. Titiyal JS, Kaur M, Singh A, Arora T, Sharma N. Comparative evaluation of femtosecond laser-assisted cataract surgery and conventionalphacoemulsification in white cataract. Clin Ophthalmol. 2016; 10:1357-64.

13. Wells GA, Shea B, O'Connell D, Peterson J, Welch V, Losos M. TheNewcastleOttawa scale (NOS) for assessing the quality if nonrandomized studies in meta-analyses. URL: Available from; 2009. http://www.ohri.ca/programs/ clinical_epidemiology/oxford.htm

14. Liberati A, Altman DG, Tetzlaff J, Mulrow C, Gøtzsche PC, loannidis JP, Clarke M, Devereaux PJ, Kleijnen J, Moher D. The PRISMA statement for reporting systematic reviews and meta-analyses of studies that evaluate healthcareinterventions: explanation and elaboration. BMJ. 2009:339:b2700.

15. Popovic M, Campos-Möller X, Schlenker MB, Ahmed II. Efficacy and safety of femtosecond laser-assisted cataract surgery compared with ManualCataract surgery: a meta-analysis of 14567 eyes. Ophthalmology. 2016;123(10):211326.

16. Lee JA, Song WK, Kim JY, Kim MJ, Tchah H. Femtosecond laser-assisted cataract surgery versus conventional phacoemulsification: refractive and aberrometric outcomes with a diffractive multifocal intraocular lens. J Cataract Refract Surg. 2019;45(1):21-7.

17. Scott WJ, Tauber S, Gessler JA, Ohly JG, Owsiak RR, Eck CD. Comparison of vitreous loss rates between manual phacoemulsification and femtosecond laser-assisted cataract surgery. J Cataract Refract Surg. 2016;42(7):1003-8.

18. Zhang X, Yu Y, Zhang G, Zhou Y, Zhao G, Chen M, Wang Y, Zhu S, Zhang H, Yao K. Performance of femtosecond laser-assisted cataract surgery in Chinese patients with cataract: a prospective, multicenter, registry study. BMC Ophthalmol. 2019;19(1):77

\section{Publisher's Note}

Springer Nature remains neutral with regard to jurisdictional claims in published maps and institutional affiliations.

Ready to submit your research? Choose BMC and benefit from:

- fast, convenient online submission

- thorough peer review by experienced researchers in your field

- rapid publication on acceptance

- support for research data, including large and complex data types

- gold Open Access which fosters wider collaboration and increased citations

- maximum visibility for your research: over $100 \mathrm{M}$ website views per year

At $\mathrm{BMC}$, research is always in progress.

Learn more biomedcentral.com/submissions 